Thành phố Hồ Chí Minh", Diễn đàn QLCL- Cục Quản lý KCB lần thứ 4.

4. Nguyển Thị Kim Yến (2015), "Nghiên cứu phân tích hành vi báo cáo sự cố y khoa tại bệnh viện Từ Dũ", Luân văn thac sỹ.

5. R. F. AbuAlRub, N. A. Al-Akour, N. H. Alatari (2015), "Perceptions of reporting practices and barriers to reporting incidents among registered nurses and physicians in accredited and nonaccredited Jordanian hospitals", J Clin Nurs.
24(19-20), tr. 2973-82

6. X. Gao, et al (2019), "Implications from China patient safety incidents reporting system", Ther Clin Risk Manag. 15, tr. 259-267.

7. S. Toyabe (2015), "Characteristics of Inpatient Falls not Reported in an Incident Reporting System", Glob J Health Sci. 8(3), tr. 17-25.

8. J. Mira et al (2014), "Hospital Reputation and Perceptions of Patient Safety", Medical Principles and Practice. 23(1), tr. 92-94.

\title{
TÌNH TRANG KIÊTT SỨC VÀ MộT SỐ YẾU TỐ LIÊN QUAN ĐẾN TÌNH TRANG KIẸT SỨC CỦA NHÂN VIÊN CHẨN ĐOÁN HİNH ẢNH TẠI BỆNH VIỆN HỮU NGHI VIỆT TIỆP - HẢI PHÒNG NĂM 2020
}

\author{
Nguyễn Bảo Trân ${ }^{1}$, Nguyễn Thị Thu Hương1, \\ Phạm Minh Khuế, Vũ Hải Vinh ${ }^{2}$
}

\section{TÓM TẮT}

Nghiên cứu cắt ngang mô tả nhằm mục đích nghiên cứu tình trạng kiệt sức và các yếu tố liển quan đến tình trạng kiệt sức của nhân viên chẩn đoán hình ảnh tại Bệnh viện Hữu nghị Việt Tiệp, Hải Phòng. Kết quả nghiên cứu cho thây tỷ lệ nhân viên bi kiêt sức cao là $20,2 \%$, trung bình là $32,9 \%$ và thấp là $46,9 \%$. Mức đô kiêtt sức của đối tượng nghiên cứu ở mức đô trung bình $(3,09 \pm 1,42)$. Theo đặc điểm cá nhân, yếu tố ảnh hưởng nhiều đến tình trang kiệt sức của nhân viên là số ngày trực trong tuần $(\beta=0,45 ; p=0,001)$. Một số yếu tố ảnh hưởng một phân đến tình trang kiệt sức của nhân viên như tuổi hay trình độ chuyền môn, thời gian công tác. Yếu tố giới không ảnh hưởng đến tình trang kiệt sức của nhân viên chẩn đoán hình ảnh.

Từ khóa: burnout, kiệt sức, nhân viên chẩn đoán hình ảnh

\section{SUMMARY \\ BURNOUT AND RELATED FACTORS OF RADIOLOGISTS IN VIET TIEP HOSPITAL, HAI PHONG - VIETNAM 2020}

This research aimed to study burnout and factors related to burnout state of radiologists in Viet Tiep general hospital, Hai Phong. The study results showed that the percentage of employees suffering from burnout was high at $20.2 \%$, the average was $32.9 \%$ and the low was $46.9 \%$. The exhaustion level of study subjects was moderate $(3.09 \pm 1.42)$. According to personal characteristics, the most influential factor affecting employee exhaustion is the number of days on duty per week $(\beta=0.45 ; p=0.001)$. Some factors partly affect the exhaustion of employees such as age

1 Trường Đại Học Y Dược Hải Phòng

${ }^{2}$ Bệnh viện Hữu Nghi Việt Tiệp, Hải Phòng

Chịu trách nhiệm chính: Nguyến Bảo Trân

Email: nbtran@hpmu.edu.vn

Ngày nhận bài: 10.3 .2021

Ngày phản biên khoa hoc: 10.5.2021

Ngày duyệt bài: 17.5.2021 or qualifications, working time. Gender does not affect the radiologist's exhaustion.

Keywords: burnout, exhaustion, radiology

\section{I. ĐẶT VẤN ĐỀ}

Thuật ngữ "burnout" được nhà tâm lý học người Mỹ Freudenberger đưa ra vào năm 1974 [1]. Ông sử dụng nó để mô tả hậu quả của việc căng thẳng nghiêm trọng và kiệt sức là một khái niệm trong căng thẳng nghề nghiệp. Kiệt sức nghề nghiệp là tình trạng căng thẳng kéo dài liên quan đến công viêc.

Bộ công cụ thường được sử dụng để đo lường tình trạng kiệt sức là Maslach Burnout Inventory (MBI). Trong đó Maslach Burnout Inventory - General Survey (MBI-GS) [2] là thang đo được sử dụng rộng rãi để nghiên cứu tình trạng kiệt sức trên nhiêu môi trường làm việc và văn hóa khác nhau.

Tất cả các ngành nghề đều có thể gặp tình trạng kiệt sức, nhưng một số nghề nhất định có nguy cơ rõ rệt như nghề chăm sóc sức khỏe [3]. Sự tiếp xúc liên tục giữa nhân viên y tế và bệnh nhân với các vấn đề tâm lý, thể chất và xã hôi liên quan của ho có thể khiến đối tương này bi căng thẳng nhiều hơn so với các nghề khác và dễ bi kiệt sức [3]. Do đó, cần có thêm các cuộc điều tra về mức độ phổ biến của tình trang kiệt sức trong ngành nghề này. Hầu hết các nghiên cứu đã được thực hiện về tỷ lệ kiệt sức của các bác sỹ, điều dưỡng, bác sỹ và kỹ thuật viên xạ trị $[4,5]$. Ngoài ra, kết quả của các nghiên cứu khác cho thây một số yếu tố như tuổi tác, giới tính, giờ làm việc mỗi tuần và kinh nghiệm làm việc đóng vai trò quan trọng trong mức độ kiệt sức trong nghề nghiệp [6]. 
Cho đến nay, rất ít nghiên cứu được thực hiện về tình trạng kiệt sức nghề nghiệp của các nhẩn viên chẩn đoán hình ảnh. Trong một nghiên cứu của Singh et al. đã chứng minh rằng mức độ kiệt sức của các nhân viên chụp X-quang, siêu âm và bác sỹ $X$-quang là cao [7]. Do đó, nghiên cứu này là nhằm mục tiêu đánh giá tình trạng kiệt sức và một số yếu tố liên quan đến tình trạng kiệt sức của nhân viên chẩn đoán hình ảnh tại Bệnh viện Hữu nghị Việt Tiệp, Hải Phòng.

\section{II. ĐỐI TƯƠNG VÀ PHƯƠNG PHÁP NGHIÊN CỨU}

2.1. Đối tượng, địa điểm, thời gian nghiên cứu. Nhân viên chẩn đoán hình ảnh (CĐHA) làm việc tại Bệnh viện Hữu nghị Việt Tiệp Hải Phòng, thời gian nghiên cứu từ $6 / 2020$ - 11/2020.

\subsubsection{Tiêu chuẩn lựa chọn}

- Là bác sỹ, kỹ thuật viên (KTV) đang công tác tại các khoa chẩn đoán hình ảnh, Bệnh viện Hữu nghị Việt Tiệp, Hải Phòng.

- Có thời gian công tác tại khoa ít nhất 1 năm kể từ khi vào làm tại bệnh viện.

2.1.2. Tiêu chuẩn loại trừ. Nhân viên chẩn đoán hình ảnh trong thời gian thử việc.

\subsection{Phương pháp}

2.2.1. Thiết kế nghiên cứu. Sử dụng nghiên cứu mô tả cắt ngang.

2.2.2. Cỡ mẫu. Chon mẫu toàn bô theo tiêu chuẩn lựa chọn: phát tổng số 90 phiếu phỏng vấn thu được 85 phiếu hợp lệ.

\subsubsection{Thu thập số liệu}

Bộ công cụ nghiên cứu gồm 3 phần:

- Phần 1: bộ câu hỏi nhân khẩu học liên quan đến thông tin đối tượng nghiên cứu: tuổi, giới,

\section{KẾT QUẢ NGHIÊN CỨU}

Bảng 1: Đặc điểm nhân khẩu học của đôii tượng nghiên cứu

\begin{tabular}{|c|c|c|c|c|c|}
\hline Đặc điếm & $\mathbf{N}$ & $\%$ & Đặc điếm & $\mathbf{N}$ & $\%$ \\
\hline Tuối: $20-29$ & 44 & 51,7 & Trình độ chuyên môn: Bác sỹ & 21 & 24,7 \\
\hline $30-39$ & 19 & 22,4 & Sau đại học & 18 & 21,1 \\
\hline$>39$ & 22 & 25,9 & Cử nhân & 46 & 54,2 \\
\hline Tống & 85 & 100 & Tống & 85 & 100 \\
\hline $\mathrm{Nam}$ & 48 & 56,5 & Tình trạng hôn nhân: Đã kết hôn & 60 & 73,2 \\
\hline Nữ & 37 & 43,5 & Chưa kê̂t hôn & 25 & 26,8 \\
\hline Tống & 85 & 100 & Tống & 85 & 100 \\
\hline \multicolumn{3}{|c|}{ Thâm niên công tác (năm) } & \multicolumn{3}{|l|}{ Số ngày trực/tuần } \\
\hline $1-5$ & 41 & 48,2 & 0 ngày & 1 & 1,3 \\
\hline $6-10$ & 19 & 22,3 & 1 ngày & 10 & 11,7 \\
\hline $11-15$ & 14 & 16,4 & 2 ngày & 59 & 69,4 \\
\hline.$>15$ & 11 & 13,1 & $>2$ ngày & 15 & 17,6 \\
\hline Tống & 85 & 100 & Tống & 85 & 100 \\
\hline
\end{tabular}

Bảng 1 trình bày kết quả đặc điểm nhân khẩu học của đối tượng nghiên cứu. Nhóm tuổi từ 20 29 chiếm tỷ lệ cao nhất trong các nhóm tình trạng hôn nhân, thời gian công tác, trình độ chuyên môn và thời gian trực trong tuần.

- Phần 2: bộ câu hỏi nghiên cứu tình trạng kiệt sức Maslach Burnout Inventory-General Survey (MBI-GS) của Maslach 1996 [2]. Bộ câu hỏi bao gồm 16 câu chia làm 3 mục: kiệt sức (5 câu); hoài nghi (5 câu); hiệu quả công viêc (6 câu) sử dụng thang điểm Likert 7 điểm (không bao giờ, rất hiếm khi, hiếm khi, thỉnh thoảng, thường xuyên, rất thường xuyên, luôn luôn) theo thứ tự điểm từ 0 đến 6 . Bộ MBI-GS đã được tác giả Nguyễn Thị Thu Hương dịch sang tiếng Việt và chuẩn hóa [8]. Cách phân loại mức độ kiệt sức [2]:

+ Kiêt sức: cao $\geq 3.2$; trung bình: 2,01 3,19 ; thấp: $\leq 2,0$.

+ Hoài nghi: cao $\geq 2,2$; trung bình: 1,01 2,19; thấp: $\leq 1,0$.

+ Hiệu quả công việc: cao $\geq 5,0$; trung bình: 4,01 - 4,99; thấp: $\leq 4,0$.

\subsection{Xử lý và phân tích số liệu}

- Sử dụng phần mềm SPSS 20.0 nhập và phân tích số liệu.

- Sử dụng tần suất và tỷ lệ phần trăm để mô tả dữ liệu nhân khẩu học.

- Sử dụng cách phân loại kiệt sức của MBI-GS để đánh giá tình trạng kiệt sức.

- Sử dụng hồi quy đa biến để khảo sát các yếu tố liên quan đến tình trạng kiệt sức.

2.4. Đạo đức nghiên cứu. Nghiên cứu được sự đồng ý của lãnh đạo bệnh viện và các khoa, phòng liên quan. Nhân viên chẩn đoán hình ảnh tự nguyện tham gia, trả lời phỏng vấn cũng như được giải thích rõ về đề tài nghiên cứu.
(51,7\%), trong khi đó, nhóm > 39 tuổi có tỷ lệ thấp nhất (22,4\%). Độ tuổi trung bình 32,21 (SD: 8,02). Số năm công tác trung bình là 8,16 
năm, đa số làm việc trong thời gian từ $1-5$ năm, chiếm $48,2 \%$. Đa số nhân viên có trình độ cử nhân chiếm tỷ lệ $54,2 \%$. Số nhân viên trực 2 ngày/tuần chiếm tỷ lệ cao nhất $(69,4 \%)$.

Bảng 2: Tì lệ kiệt sức cứa đôi tượng nghiên cứlu $(N=85)$

\begin{tabular}{|c|c|c|}
\hline & $\mathbf{N}$ & $\mathbf{\%}$ \\
\hline Kiệt sức: Thấp & 40 & 46,9 \\
\hline Trung bình & 28 & 32,9 \\
\hline Cao & 17 & 20,2 \\
\hline Hoài nghi: Thấp & 49 & 57,7 \\
\hline Trung bình & 22 & 25,9 \\
\hline Cao & 14 & 16,4 \\
\hline Hiệu quả công việc: Thấp & 46 & 36,5 \\
\hline Trung bình & 37 & 43,5 \\
\hline Cao & 17 & 20,0 \\
\hline
\end{tabular}

Bảng 2 trình bày tỷ lệ kiệt sức của đối tượng nghiên cứu theo từng mức đô thấp, trung bình và cao. Kết quả cho thấy, tỷ lệ nhân viên $\mathrm{C} Đ H A$ bị kiệt sức cao chiếm khoảng $20 \%$. Tỷ lệ nhân viên có sự hoài nghi cao về công viêc chỉ chiếm 16,4\%. Trong khi đó, nhân viên có tỳ lệ hiệu quả công việc trung bình lại chiếm tỳ lệ cao nhất (43,5\%).

Bảng 3: Mức đô kiệt sức của đôî tượng nghiên cứu (N = 85)

\begin{tabular}{|c|c|}
\hline & Mean \pm SD \\
\hline Kiệt sức & $3,09 \pm 1,42$ \\
\hline Hoài nghi & $2,65 \pm 1,64$ \\
\hline Hiệu quả công việc & $4,80 \pm 0,57$ \\
\hline
\end{tabular}

Bảng 3 cho thấy mức độ kiệt sức của đối tượng nghiên cứu lần lượt là kiête sức 3,09 \pm 1,42 ; hoài nghi $2,65 \pm 1,64$; hiệu quả công việc $4,80 \pm 0,57$.

Bảng 4: Các yếu tố liên quan đến tình trạng kiệt sức của đôí tượng NC theo đặc điểm nhân khâu học

\begin{tabular}{|c|c|c|c|c|c|c|}
\hline & \multicolumn{2}{|c|}{ Kiêtt sức } & \multicolumn{2}{|c|}{ Hoài nghi } & \multicolumn{2}{|c|}{ Hiệu quả công việc } \\
\hline & $\beta$ & $p$ & $\beta$ & $\mathrm{p}$ & $\beta$ & $p$ \\
\hline Tuối & & & 0.14 & 0.038 & -0.26 & 0.001 \\
\hline Tình trạng hôn nhân & & & & & 0.13 & 0.026 \\
\hline Giới & & & & & & \\
\hline Năm công tác & & & & & 0.24 & 0.014 \\
\hline Số ngày trực/tuần & 0.45 & 0.001 & 0.35 & 0.002 & -0.18 & 0.004 \\
\hline Trình độ chuyến môn & & & -0.16 & 0.009 & & \\
\hline Tống $R^{2}$ & \multicolumn{2}{|c|}{0.20} & \multicolumn{2}{|c|}{0.23} & \multicolumn{2}{|c|}{0.25} \\
\hline Tống $R^{2}$ hiệu chỉnh & \multicolumn{2}{|c|}{0.14} & \multicolumn{2}{|c|}{0.19} & \multicolumn{2}{|c|}{0.21} \\
\hline
\end{tabular}

*Stepwise Multiple Regression

Bảng 4 cho thây các yếu tố tác đông đên tình trang kiệt sức theo đặc điểm cá nhân của đối tượng nghiên cứu. Kết quả cho thấy yếu tố giới không phải là nguyên nhân dẫn đến tình trạng kiệt sức của nhân viên $\mathrm{C} Đ H A$. Đặc biệt, số ngày trực trong tuân ảnh hưởng đến cả ba yếu tố của tình trạng kiệt sức, trong đó tác động nhiều nhất đến mục kiệt sức $(\beta=0,45)$.

\section{BÀN LUÂN}

Nghiên cứu đánh giá tình trạng kiệt sức cho thây tình trạng kiệt sức của đối tượng nghiên cứu ở mức độ trung bình, sự hoài nghi với công việc ở mức đồ cao, hiệu quả công việc ở mức đô trung bình. Theo Singh và cộng sự cho thấy điểm số kiêtt sức, hoài nghi, và hiệu quả công việc đối với nhân viên chụp X-quang ở mức độ kiểt sức cao [7].

Trong nghiên cứu của chúng tôi, mức độ kiệt sức thấp hơn so với báo cáo cho các bác sĩ Xquang ở Úc và New Zealand [7] và cho các nhân viên khoa ung thư ở New Zealand và Hoa Kỳ [9]. So sánh các kết quả chỉ ra rằng mức độ kiệt sức rất khác nhau giữa các ngành nghề khác nhau.
Điều này có thể do nhiều yếu tố như các chính sách, các tiêu chí nghề nghiêp và điều kiện làm viêc.

Nghiên cứu về các yếu tố liên quan ảnh hưởng đến tình trạng kiệt sức của nhân viên CĐHA, kết quả cho thây, thời gian trực trong tuần có ảnh hưởng lớn đến tình trạng kiêt sức của nhân viên. Kết quả chỉ ra rằng số ngày trực tăng một ngày thì tình trạng kiệt sức tăng 49\% và sự hoài nghi tăng $35 \%$ nhưng hiệu quả công viêc giảm đến $18 \%$. Các yếu tố nhẩn khẩu học cũng được coi là các yếu tố góp phần gây ra tình trang kiềt sức một phần như thời gian công tác hay trình độ chuyên môn hoặc ảnh hưởng toàn diện đến tình trang kiệt sức như thời gian trực trong tuần. Tuy nhiên, ở nghiên cứu này thì yếu tố giới không phải là nguyên nhân gây nên tình trang kiêt sức. Một số nghiên cứu phát hiên ra rằng mức đô kiêtt sức ở nữ cao hơn ở nam [10] trong khi những nghiên cứu khác cho biết giới tính không phải là yếu tố đáng kể đối với mức độ kiệt sức. Ở một số nghiên cứu khác cho thấy kinh nghiêm làm việc và tuổi tác tăng lên ở nhân viên CĐHA có tương quan đáng kể với điểm 
thang đo MBI. Tương tự như vậy, một số nghiên cứu cho thấy rằng những nhân viên trẻ hơn hoặc những người có kinh nghiệm làm việc thấp hởn đã trải qua mức độ kiệt sức cao hơn ở Iran và các quốc gia khác [4].

Những kết quả này chứng minh rằng những năm đầu của nghề có thể là những năm thử thách nhất. Lý do có thể đằng sau vấn đề này nằm ở việc các nhân viên lớn tuổi trải qua nhiều tình huống khác nhau tại nơi làm việc theo thời gian và họ có thể dần học được cách xử lý các tình huống khó khăn. Do đó, những đối tượng này có thể ít gặp phải tình trạng kiệt sức hơn. Ngoài ra Singh và cộng sư cho thây tuổi tác và kinh nghiệm làm việc không ảnh hưởng đến mức độ kiệt sức của các bác sỹ X-quang [7].

\section{KẾT LUẬN}

Nghiên cứu cắt ngang cho thấy tình trạng kiệt sức của đối tượng nghiên cứu ở mức độ trung bình. Các yếu tố ảnh hưởng đến tình trạng kiệt sức chủ yếu do thời gian trực trong tuần kéo dài, trình độ chuyên môn, thâm niên công tác chỉ tác động một phần đến tình trạng kiệt sức. Trong khi đó, thì thời gian trực trong tuần yếu tố ảnh hưởng mạnh mẽ đến tình trạng kiệt sức của điều dưỡng. Từ kết quả này gợi ý cho các nhàn quản lý có cái nhìn tổng quan về tình trạng kiệt sức của đối tượng này và có các chính sách hay cách giải quyết phù hợp nhằm ngăn ngừa tình trạng kiệt sức.

TÀI LIỆU THAM KHẢO
1. Depression: what is burnout? https://www.ncbi.nlm.nih.gov/books/NBK279286/ updated on January 12, 2017.

2. Maslach C, Jackson SE, Leiter MP. Maslach Burnout Inventory Manual. 3rd ed. Menlo Park, CA: Mind Garden; 1996.

3. Klersy C, Callegari A, Martinelli V, Vizzardi V, Navino C, Malberti F, et al. Burnout in health care providers of dialysis service in Northern Italy-a multicentre study. Nephrol Dial Transplant. 2007; 22(8): 2283-90.

4. Demirci S, Yildirim YK, Ozsaran Z, Uslu R, Yalman D, Aras AB. Evaluation of burnout syndrome in oncology employees. Med Oncol. 2010; 27(3): 968-74.

5. Nguyê̂̃n Thị Thu Hương, Phạm Minh Khuê, Nguyển Thị Minh Ngọc, Phạm Thanh Hải. Nghiên cứu tînh trạng kiệt sức của điều dưỡng viên lâm sàng tại bệnh viện Việt Tiệp, Hải Phòng năm 2019. Tap chí y hoc dự phòng 2019; 29(9): 94-102.

6. Rezaei O, Habibi K, Arab Ghahestany D, Sayadnasiri M, Armoon B, Khan $V$, et al. Factors related to job burnout among nurses in the Razi Psychiatric Hospital, Iran. Int J Adolesc Med Health. 2018.

7. Singh N, Knight K, Wright C, Baird M, Akroyd D, Adams RD, et al. Occupational burnout among radiographers, sonographers and radiologists in Australia and New Zealand: Findings from a national survey. J Med Imaging Radiat Oncol. 2017; 61(3):304-10.

8. Nguyen HTT, Kitaoka $K$, et al. Burnout Study of Clinical Nurses in Vietnam: Development of Job Burnout Model Based on Leiter and Maslach's Theory. Asian Nursing Research 2018; 12(1): 42-49.

9. Akroyd D, Caison A, Adams RD. Burnout in radiation therapists: The predictive value of selected stressors. Int J Radiat Oncol Biol Phys. 2002; 52(3): 816-21.

\section{ĐĂC ĐIỂM LÂM SÀNG VÀ CÂ̂N LÂM SÀNG CÁC TRƯờ'NG HỢP CHỬA SẸO MỔ LẤY THAI ĐƯợC PHẪU THUÂ̂T TẠI BỆNH VIỆN PHỤ SẢN TRUNG ƯO'NG}

\section{TÓM TẮT}

Mục tiêu: Mô tả đặc điểm lâm sàng và cận lâm sàng các trường hợp chửa sẹo mổ lây thai được phẫu thuật tại Bệnh viện Phụ sản Trung ương. Phương pháp: Tiến cứu mồ tả. Kết quả: Triệu chứng ra máu âm đạo chiếm 49,2\%, đau bụng với ra máu âm đạo chiếm $22 \%$, triêuu chứng băng huyết chiếm $5,1 \%$. Trền siêu âm là khối âm vang hỗn hợp chiếm $42,4 \%$, tuổi thai từ 8 tuần trở lên chiếm 35,6\%. Biến chứng chảy máu phải truyền máu nhiều nhất nhóm có nồng độ

*Bệnh viện Phù sản Trung ương

Chịu trách nhiệm chính: Nguyễn Quảng Bắc

Email: drbacbvpstw@gmail.com

Ngày nhận bài: 9.3.2021

Ngày phản biện khoa học: 7.5.2021

Ngày duyệt bài: 17.5.2021

\section{Nguyễn Quảng Bắc*, Vũ Ngân Hà*}

ßhCG trước điều trị < $10.000 \mathrm{mUI} / \mathrm{ml}$ chiếm 42,9\%, giải phẫu bênh gai rau thoái hóa chiếm tỷ lệ cao nhất là 69,5\%. Kết luận: Triệu chứng lâm sàng là ra máu ít một và siêu âm cho kểt quả chính xác chưa sẹo mổ lấy thai.

Tư khoá: Chửa sẹo mổ lấy thai.

\section{SUMMARY}

CLINICAL AND SUBCLINICAL

\section{CHARACTERISTICS OF CESAREAN SCAR SECTION AT NATIONAL HOSPITAL OF OBSTETRICS AND GYNEACOLOGY}

Objectives: To describe clinical and sub-clinical characteristics of cesarean scar section which was operated at National hospital of Obstetrics and Gyneacology. Methodology: This is a prospective study. Results: Vaginal bleeding was $49.2 \%$, bleeding with pain was $22 \%$, hemorrhage was $5.1 \%$. 